\title{
ENTREVISTA SOBRE FEMINICIDIO DESDE UNA PERSPECTIVA SOCIOLÓGICA
}

1.

Si bien es cierto que la incorporación del feminicidio en la legislación

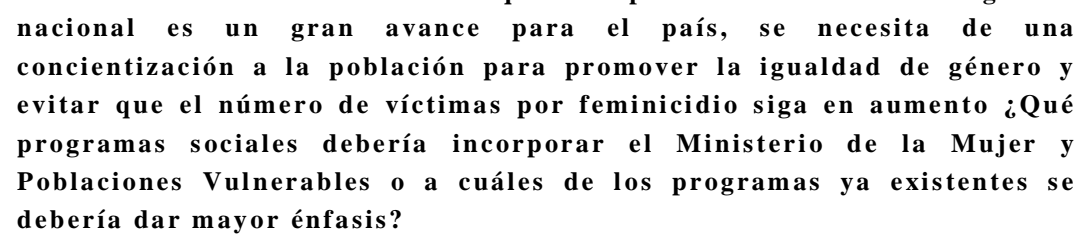

En realidad, el tema de feminicidio en el Perú se trabaja desde hace pocos años. En el Estado, se asume a partir del año 2009 justamente por las acciones de incidencia política que realizamos las organizaciones de mujeres, entre ellas Flora Tristón, como una de las pioneras en trabajar el tema del feminicidio. Una de las primeras políticas que el Estado establece es el registro de víctimas del Ministerio Público, que es uno que sale a inicios del 2009 y luego le sigue el del MIMDES (Ministerio de la Mujer), esos son dos registros diferenciables. Una de las propuestas que nos parece que sería la más adecuada sería no desaparecer alguno de los dos registros, sino más bien unificarlos y tener así un registro un poco más amplio de los casos de feminicidio. Luego, existe el feminicidio, dentro del Plan Nacional contra la Violencia hacia la Mujer, hay un objetivo que tiene que ver con la transformación cultural, donde se señalan una serie de investigaciones para abordar el tema del feminicidio. Otra de las políticas que se ha estado impulsando, es justamente la nueva normatividad, que se supone que este año tendría que hacerse realidad. Sin embargo, todo eso resulta importante, pero insuficiente. Lo primero que necesitaríamos, sería un programa amplio contra la violencia hacia las mujeres. Existe el Programa contra la Violencia Familiar y Sexual del MIMDES, lamentablemente el presupuesto con el que cuenta este programa es bastante limitado. Existe una continua tendencia a no hablar de la violencia contra las mujeres, sino más bien, colocar a la mujer no como una sujeta de derechos en sí, sino dentro de un colectivo de la familia, si bien es cierto, la violencia familiar es un problema grande e importante en nuestro país, en el caso de la violencia familiar, las principales víctimas son las mujeres, las niñas y los niños, pero principalmente las mujeres. El problema del feminicidio no pasa solamente por un problema solamente de índole familiar, sino que normalmente se sitúa dentro de lo que son las relaciones desiguales entre las parejas, en el contexto de la violencia entre las parejas, 
situación de conflicto básicamente, para erosionar ello necesitaríamos afianzar el "Programa contra la Violencia Familiar y Sexual" y dirigirlo más a que aborde la causas estructurales que restringen la ciudadanía de las mujeres. Es decir, causas como el patriarcado, como un capitalismo desliumanizado que juntos se retroalimentan para colocar a las mujeres en una situación constante de vulnerabilidad. Necesitaríamos programas que puedan generar trasformaciones culturales, ya que el problema de violencia hacia las mujeres no es un problema legal. El Derecho es una herramienta de cambio importante, pero el problema no es legal, es más bien un problema social. Entonces toda norma que aparezca contra el feminicidio va a resultar insuficiente si no se generan políticas públicas para su prevención, para transformar la imagen de la mujer en la sociedad, colocarla como una sujeta de derechos y en una situación de igualdad de derechos y condiciones para lo cual se tiene que generar políticas afirmativas que muchos pueden considerar discriminatorias hacia los hombres pero que en realidad lo que buscan es equiparar el piso de oportunidades con el que no nacen las mujeres con el objetivo de que finalmente se equiparen, ya que la situación de desigualdad de las mujeres es histórica. Necesitamos de políticas que puedan cambiar la cultura y el cómo las personas ven a las mujeres, que las vean como sujetos de derechos, no solo dentro de un colectivo, sino como un sujeto independiente. La mayoría de políticas públicas no contribuyen a combatir las causas estructurales que sustentan la violencia contra las mujeres que solamente se puede desarrollar en una democracia. Cuando no hemos estado en un régimen democrático, los derechos de las mujeres aparentemente se han incrementado, pero en realidad no, porque, por ejemplo, durante el gobierno fujimorista se dieron las principales normas; se dio la Ley de Violencia Familiar (Ley 26260), Defensoría del Pueblo, PROMUDEH que actualmente es el Ministerio de la Mujer y Poblaciones Vulnerables; sin embargo, se generó una política muy asistencialista que no ayudó a que las mujeres sean colocadas como sujetos de derecho, y esa en una de las grandes trampas que provoca que la violencia contra las mujeres continúe. Porque la violencia contra la mujer nace y se utiliza como un medio de control, los agresores utilizan la violencia como un medio de control para situar a las mujeres en el rol que les corresponde, mientras no erosionemos eso, pueden haber todas las leyes, podemos seguir trabajando por las mejores leyes, nos podemos convertir en uno de los países en Latinoamérica con un sistema de leyes de vanguardia, pero no vamos a solucionar el problema. debe de dar el Ministerio de Educación a fin de que se pueda lograr este objetivo?

En realidad el Ministerio de Educación es uno de los grandes ausentes en el tema de violencia de género. Se ha demandado muchas veces que el Ministerio de Educación pueda coordinar conjuntamente con el Ministerio de la Mujer y a su vez con las organizaciones que trabajan el tema de violencia de género contra las mujeres. La educación continúa siendo sexista; es decir, perpetúa estereotipos de género. Ahora las mujeres tiene que ser súper mujeres y ello va repercutir en la educación. Se tiene la idea de las "súper mujeres", "súper madres", profesionales, amigas, esposas, tienen que ser excelentes en todo. Mientras los hombres tienen que ser "excelentes trabajadores". Hay una obsesión muy fuerte hacia las mujeres y eso se refleja en la educación, por tal sería bueno que se revise la curricula con enfoque de género. 
donde se deje de colocar a las mujeres como madres, como modelos o como súper seres humanos. Considero que la educación es sumamente sexista y perpetúa muchas imágenes de lo que debe ser la mujer; bonita, madre, trabajadora, delgada, modelo a seguir; es decir, hay una serie de exigencias. No es que no hayan asignado a la mujer nuevos roles como el de ser trabajadoras, sino que a esos roles se han sumado otros y se afianzan otros más y finalmente se convierte en una obsesión mediática sobre cómo tiene que ser una mujer. Entonces, hay una presión constante y eso no contribuye a erosionar los estereotipos de género y más bien combina los estereotipos de género con los estereotipos generacionales. Hay un gran espacio de caducidad de las mujeres, que crea estereotipos, presión, discriminación y en un país como el Perú, con tanta diversidad, si a esos dos estereotipos, tanto de género como generacional se le suma un estereotipo de raza, vemos que la gran mayoría de las mujeres son discriminadas y algunos espacios de Lima vienen a convertirse en una especie de guettos extraños del país, porque todo es resto del país tiene otra realidad y como la mayoría de la población con más poder está en Lima parece que el Perú fuese fantástico, pero en el resto del país hay mucha discriminación. No es lo mismo ser una mujer pobre, andina o amazónica, o ser una adulta mayor o niña. Todas esas situaciones se entremezclan para crear mayores situaciones de exclusión y eso nos evidencia de que en realidad no es que no haya igualdad, y que se hayan superado las condiciones de desigualdad, sino de que las desigualdades permanecen fuertemente en nuestra sociedad, se retroalimentan de otras situaciones de desigualdad y generan graves problemas como los que tenemos actualmente, como es el tema de las nanas en los clubes, en donde una persona es tratada como una esclava, así como en el uso de uniformes para las trabajadoras del hogar con el fin de ser diferenciadas. Eso parte de la educación y de cómo es la educación diferencial en los colegios en nuestro país, pues no es lo mismo una educación en un colegio privado donde se tienen mayores oportunidades, que la de un colegio público, no solo en temas de conocimiento, sino también en temas de estereotipos que se van replicando en diferentes formas. Todo ello va a profundizar las condiciones de discriminación. Una vez escuché a una feminista decir que todo derecho ganado para las mujeres es un derecho humano ganado para todos y para todas, esas palabras me parecieron muy sabias porque un derecho humano que le es garantizado a las mujeres, no tiene que ser peleado para los hombres, o sea que ya es un derecho ganado para todos. Más bien somos la mujeres las que hemos tenido que luchar por nuestros derechos a lo largo de la historia, y no me sorprende, que por supuesto todo el mundo cuando la mayoría de personas habla de los derechos de las mujeres les "da alergia", que porqué el derecho de las mujeres y no el de los hombres. Los derechos de los hombres ya están allí, y estarán allí siempre, nosotras los hemos tenido que luchar en cuanto a derechos humanos de las mujeres.

Esperemos que el Ministerio de Educación tome medidas en las que puedan tener programas donde se contribuya a construir la masculinidad, por ejemplo, no se trata de solamente de crear feminidades, en donde las mujeres nos apoderemos y seamos cada vez más autónomas, sino también de crear nuevas masculinidades, porque hombres y mujeres convivimos en la sociedad y necesitamos crear masculinidades, tanto en hombres como en mujeres, para que las mujeres también puedan apoyarlas. Esa parte es muy importante. Nuevas feminidades y masculinidades, son los grandes retos que tiene el sector educación. En los colegios por ejemplo, todavía se mide el valor en los hombres; en función a la fuerza, a lo avezados que pueden ser, entonces hay que hacer una revisión exacta de cómo se están educando a hombres y mujeres. 
Siento que el Ministerio de Educación no se ha comprometido mucho con el tema y evidencia de ello es que existen profesores que han sido acusados de violencia sexual contra las niñas y niños, pero principalmente contra las niñas, y lo único que ha pasado es que se han ido a trabajar a otros colegios. Entonces, estamos creando un gran problema hacia las mujeres, que es la impunidad. No es que no existan normas, sino que no se cumplen, hay mucha impunidad. Cuando hay impunidad hay un mensaje muy fuerte de que una determinada cosa se puede hacer y que no va a pasar nada.

En cuanto al tema de la impunidad los agresores, ello se refleja en el caso de las Comisaría de las Mujeres, pues primero le tienen miedo, pero cuando se dan cuenta de que no les va a pasar nada, pierden el miedo. Los hombres han aprendido cómo golpear, es por eso que creo que también en parte ha aumentado la violencia psicológica, si bien se puede deber a que exista más información para las mujeres y estas se animan a denunciar más, pero también porque los agresores saben qué y dónde hacer golpear a efectos de que las lesiones no sean visibles, por eso es que el Ministerio de la Educación debe tomar medidas. Cuando hablamos de educación no podemos solo hablar de la educación en los centros educativos, sino en los centros de formación; por ejemplo, en los institutos, en las universidades. Hay casos en los que todavía no llega la justicia y si bien es cierto que la educación se da en los colegios, también se da también en su primer círculo de socialización, que son las familias. Lo primero que se tiene que buscar es respetar la diversidad. Hay que repensar lo que se está entendiendo por familia. Estamos entendiendo por familia la unidad de un conjunto de personas que se aman, que tienen lazos de solidaridad y de parentesco o estamos entendiendo la unidad de un hombre y una mujer. En función a entender qué es la familia, es que se ha cometido los grandes crímenes. Y las mujeres son las grandes víctimas de la defensa de la familia, porque son lo que son según el rol social histórico que le corresponde, se les ha impuesto a las mujeres el rol de las grandes cuidadoras de la familia, en función a este rol es que se les ha negado una variedad de derechos y posibilidades.

Regresando al tema del feminicidio, el caso de Ciudad Juárez es emblemático y está caracterizado por las alarmantes cifras de feminicidio, así como por la extrema violencia y ensañamiento con la que son asesinadas las mujeres ¿cuáles cree que han sido los factores que han llevado a esta ciudad a tal situación?

El caso de Ciudad Juárez es un caso especial, no es un caso como el peruano. La palabra feminicidio nace en Estados Unidos más o menos en el año 92 en este año, Diana Russell principalmente, acuña la palabra 'femicide" para denominar los asesinatos de mujeres en situaciones de violencia de género, generalmente por sus parejas. Luego, en Latinoamérica este tipo de asesinatos empieza a ser más conocido a partir de Ciudad Juárez. A partir de esto, es que en México se toma el término y empieza a hablarse de feminicidio. La correcta traducción sería "femicidio", pero en México lo tradujeron a "feminicidio". Alguna de las personas que apoyaba este término en Latinoamérica es Marcela Lagarde. quien dice que en esta palabra la sílaba "ni" representa la impunidad en México, porque existe mucha impunidad con respecto a la violencia contra las mujeres. Nosotros en Perú hemos tomado el término feminicidio, con todas las características que este involucra.

El caso de Ciudad Juárez es característico, pues se vincula mucho a los cambios en la economía mundial. Ciudad Juárez tiene una economía basada en las ma- 
quilas. Las mujeres empiezan a trabajar en las maquilas y empiezan a ocupar puestos laborales, que tradicionalmente eran ocupados por hombres y es entonces cuando las mujeres empiezan a ser asesinadas, pero no solamente eso, en Ciudad Juárez no solamente se mezcla el tema económico, sino también el tema del narcotráfico y de las bandas organizadas. Es éste uno de los espacios donde se puede apreciar con más claridad cómo el patriarcado junto con el capitalismo deshumanizado se mezclan para sumergir a las mujeres en una situación de discriminación y violencia muy descamada. Porque la economía, o más bien, el capitalismo en sí determinaron tal forma de empleo a las mujeres, lo cual originó que las mujeres se vean desprotegidas completamente. Esta es una ciudad fuertemente patriarcal. Los asesinatos en Ciudad Juárez son terribles, las mujeres son asesinadas, son mutiladas, abandonadas en terrenos baldíos y muchas veces escriben en los cuerpos de las mujeres lo que representa una demostración de poder, una especie de sanción, de demostración de poder, donde se sanciona algo que consideran que está fuera de los parámetros, de lo que los agresores consideran correcto. No solo se habla de feminicidio con respecto a mujeres desprotegidas, si bien es cierto que la mayoría son mujeres pobres que trabajan en esas maquilas que no cuentan con ninguna condición de seguridad, sumado todo con el tema del narcotráfico, también muchas han sido víctimas de feminicidio por venganza. Es una ciudad muy violenta, donde las mujeres son las principales víctimas de esta violencia. La crueldad es una forma de evidenciar el poder, la crueldad sobre el cuerpo de las mujeres es una forma de decir "este cuerpo es mío y yo hago lo que quiera con este cuerpo". Las mujeres son utilizadas como armas para demostrar el poder.

4.

Retornando al contexto peruano, ¿considera que el Estado ofrece las garantías de protección y prevención para con la mujer, para que los abusos sean denunciados y no sean parte de la cifra de abusos no reportados? ¿Existe actualmente alguna política de Estado que asegure la presencia del mismo en zonas remotas?

No, no existe. Aún falta mucho. Partiendo del hecho de que una mujer que denuncia tiene que volver a su casa y simplemente se cita al agresor, no hay protección. No hay suficientes casos de acogida, hay más casos de acogida en la sociedad civil que en el Estado. Entonces no hay. La ruta está mal pensada, porque las mujeres no se sienten protegidas. No es que denuncian y luego van a algún lado o que se van a tomar medidas contra el agresor, sino que las mujeres denuncian y tienen que volver al mismo lugar donde están con el agresor, entonces eso no es protección.

La mayoría de servicios que existen en el país para evitar la violencia tiene un modelo urbano. Ha habido algunos intentos, algunos proyectos para repensar los modelos de atención, pero no es que estén en todos los lugares. Hay algunos Centros de Emergencia Mujer que solo están en algunas provincias. Las Comisarías de Mujeres, creo que solo hay 27 o 28 en todo el país. Este es un país que le da la espalda a la diversidad tanto situacional como étnica. Necesitamos servicios que puedan garantizar que, por ejemplo, en la zona de Junín que habla principalmente asháninca existan operadores que también hablen este dialecto, y por ley se tendrá que garantizar esto. Entonces no hay medios de atención adecuados a cada cultura. Y claro, esto representaría un costo alto para el Estado, pero es algo en lo que se tiene que invertir. Por ejemplo, si revisamos el presupuesto del Estado, el tema de violencia contra las mujeres tiene uno de los presupuestos más bajos. En una reunión con el MIMP, veíamos que el programa de "Violencia familiar y Sexual", tenía el $0.3 \%$ del presupuesto del 
MIMP, entonces, si en el MIMP tenía un promedio ínfimo, dentro de este, ¿cuál será el promedio con respecto al Estado? Entonces una de las luchas de las organizaciones de mujeres es que los presupuestos sean sensibles al género; es decir, que en todos los presupuestos esté involucrado el tema de género, pero que, principalmente, se garanticen mayores recursos para combatir la violencia contra las mujeres, no basta con una Ley de feminicidio, la tipificación tiene que ir acompañada de políticas públicas para la prevención, siempre y cuando funcionen también, no basta simplemente la ley, porque ninguna ley va a dar solución a ningún problema, ya que el problema del feminicidio no es un problema legal. El Derecho es una herramienta para el cambio, pero es una herramienta, no es la solución, si no va acompañada de políticas públicas no va a funcionar.

En esta misma línea, las políticas públicas de seguridad ciudadana tienen que tener enfoque de género, porque la ciudad las mujeres la vivimos de diferente forma, las mujeres le tenemos más miedo a la ciudad. En el Perú, el sistema de atención para la violencia es pobre; por otro lado, los fiscales y jueces están sobrecargados de trabajo, la violencia es tanta, que están sobrecargados. Tiene que haber más juzgados especializados, más comisarías de mujeres, más Centros de Emergencia Mujer pero con atención de calidad, de acuerdo a cada contexto cultural, pues no podemos utilizar el mismo modelo para todas las realidades porque lo que hacemos finalmente es que las personas se alejen del Estado. 